\title{
Reinventing Medical education in the COVID-19 era
}

\author{
Saswati Das ${ }^{1,2}$ \\ ${ }^{1}$ Department of Biochemistry, Dr. Ram Manohar Lohia Hospital and Post Graduate Institute of Medical Research, \\ New Delhi-110001, India, ${ }^{2}$ Department of Biochemistry, Central Government Health Services, New Delhi-110066, India
}

Since the beginning of the year 2020, COVID-19 pandemic has engulfed the whole world. Many cities across the globe have been under lockdown during this outbreak and the regular classes, clinical, laboratory sessions have been suspended in most medical schools. In the midst of this pandemic, we have had to reinvent the pedagogy of undergraduate medical teaching. The ongoing crisis has motivated medical teachers to come up with a contingency plan for continuing training in the face of adversary. As in-person training had to be avoided, the traditional methods of teaching like didactic lectures, tutorials, case discussions and practical laboratory sessions were of no value in the midst of this pandemic. This led the educationists to explore e-learning resources in order to carry on the medical school training program. There are several challenges in designing a successful e-learning program. Medical institutions must identify sustainable e-learning solutions specially in resource-constrained settings. This perspective article discusses how medical education has been affected by COVID-19 around the world and how it has made educators rethink their teaching strategy. The paradigm shift to e-learning during this outbreak may encourage medical schools to revisit and redesign their curriculum to more versatile programs in future. The experiences gathered during this period might bring about groundbreaking changes in how medicine is taught.

Key words: Medical Education; Pedagogy; COVID -19; Pandemic

\section{Access this article online}

Website:

http://nepjol.info/index.php/AJMS DOI: 10.3126/ajms.v12i2.32707

E-ISSN: 2091-0576

P-ISSN: 2467-9100

Copyright (c) 2021 Asian Journal of Medical Sciences

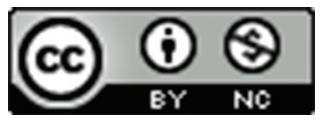

This work is licensed under a Creative Commons Attribution-NonCommercial 4.0 International License.

\section{INTRODUCTION}

COVID-19 is spreading rapidly through different continents. The mainstay of the control measures implemented by the governments has been quarantine, isolation and infectioncontrol measures to prevent disease spread, supportive care for those who become ill. With many cities under complete lockdown, the institutions of medical education have been closed temporarily. A classroom is a gathering that could be a potential high risk zone. Traditional methods of teaching like didactic lectures, tutorials, case discussions and practical laboratory sessions hold no value in the midst of this pandemic. This has led the educationists to turn to e-learning resources. This change in the pedagogic approach was probably long due. This perspective article discusses how the COVID-19 pandemic has impacted undergraduate medical education and what will be the long time repercussions of this outbreak on medical education.

\section{MEDICAL EDUCATION BEFORE COVID-19}

In the past decade medical colleges have been trying to introduce pedagogic reforms and reduce the emphasis on traditional lecture. More interactive teaching learning methods have been introduced like team based learning, problem based learning, small group discussions, skill labs etc. With the advent of technology many medical schools have been trying to incorporate, e-resources in their curricula. Curriculums around the world have been modified to encourage competency-based learning. However the incorporation of e-learning has been a challenge. A successful e-learning program requires a dedicated team of technologist, logistics, administrative support apart from a enthusiastic learner and educator. ${ }^{1}$ Implementation of learning management system is advocated for smooth dissemination of virtual learning. ${ }^{2}$ Most medical institutions have been reluctant in building the infrastructure that harbours e-learning. ${ }^{3,4}$ 


\section{WHAT CHANGED AFTER THE PANDEMIC?}

Large gatherings are prohibited as part of preventive strategy in COVID-19. With social distancing being the new norm, traditional classroom teaching could no longer be carried out during this crisis. The mainstay of disseminating information that has emerged in this pandemic has been video lectures, webinars, seminars and journal clubs via video-teleconference. These sessions are recorded so that they could be accessed by individuals, who were not able to join the session at a later time. A variety of methods including, video conference networks like zoom, digital learning platforms, distance learning networks, digital libraries, learning management systems, virtual simulations, mobile applications, game based learning platform and other e-resources, are being used by different medical schools. ${ }^{5-7}$ Assignments are being sent to students to be completed within a stipulated period. E-assessment by inclusion of online quiz, virtual OBE (Open Book Exam), log books, e-portfolio may be considered for formative and summative assessments by various departments. ${ }^{8,9}$

Continuing the medical pedagogy without the live patient is a huge challenge. An ideal scenario for imparting clinical knowledge is always a live patient, with whom the medical student or trainee can interact, elicit the disease history and in the process learn to empathize with the patient which improves their communication skills. However, in the event of the pandemic, any such contact is detrimental to patient care and puts the student at risk. Hence the live patient has to be replaced with a simulated patient and mannequins for practicing procedures. Assessments in clinics can be planned with the assistance of virtual patients, mannequins, remote OSCE (Objectively Structured Clinical Examination), video based vice voce. ${ }^{9-11}$

\section{AN UNPRECEDENTED CHALLENGE}

Pandemics are extraordinary circumstances that pose unusual challenges to medical teachers. Clinical rotations are usually withheld for the students because of limitation of live patient interaction. Online teaching learning methodology had to be incorporated in our curriculum as in person teaching was not recommended during this outbreak. In our department we started taking lectures, tutorials and problem based learning via Google Meet (Google Inc, USA) and Zoom (Zoom Video Communications Inc., USA). Zoom breakout sessions post lectures with residents were held to solve the queries of the students. Clinical cases were discussed using patient surrogates, audio-taped recordings shot with student volunteers. Assessment has also been conducted by using online quiz, multiple choice questions, short answer questions and viva voce via Zoom in our institute. For practical skills assessment we are considering onlineOSPE (Objectively Structured Practical Examination).

The key barriers to the implementation of online learning in the midst of this pandemic are time constraints of faculty, poor technical skills, inadequate infrastructure, and absence of institutional planning. To solve these conundrums it is imperative improve educator skills. Training and retraining of the educators, of the available e-resources should be organized. Improved institutional support \& building the necessary infrastructure should ease the delivery of information. The switch to e-learning also benefits the students who are becoming a part of the workforce everyday by volunteering their services as the video lectures are archived by most schools and can be accessed at the convenience of the user. This ensures that the student volunteers do not miss out on their education. Institutions must identify sustainable e-learning solutions for use in resource-constrained settings; analyse the effect of these modalities in decreasing the already constrained faculty time with the primary focus being on care of the COVID-19 patients.

\section{EVOLVING ROLE OF MEDICAL STUDENTS IN THIS PANDEMIC}

Medical students across the continuum of education have dedicated their services in many ways to care for patients and communities in this crisis. In medical schools across the globe, students are volunteering in creating patient education materials, online awareness programmes, helping out at old age homes. Keeping in mind a situation that might lead to health care worker shortage, students may need to be engaged as part of the workforce. Healthcare services worldwide are under immense pressure, with medical teams suffering from loss of quarantined residents and nurses. Medical students are a highly skilled workforce who can be utilized during this crisis. Students with training in clinical departments, specifically the fourth year students can help in the triage areas, take patient histories, call patients with laboratory test results, document visits, and assist the clinical teams. ${ }^{12}$ General Medical Council United kingdom is providing provisional registration for final year medical students once their medical school assesses their application and deems them eligible for the same. ${ }^{13}$ Some medical schools are considering early graduation.

Medical students can also be the best volunteers during this period. Medical students can assist in the care of COVID-19 patients by monitoring patients with mild 
COVID-19 symptoms who are not admitted remotely; by reviewing their charts, drafting notes, and ensuring laboratory tests are performed; and following -up with patients after discharge. ${ }^{14}$ As volunteers they may not be assigned the duties of a clinical doctor and should remain under constant supervision. The involvement of medical students in the care of COVID-19 patients should be limited as they are still under training and only allowed in worst circumstance. Issues such as health insurance of medical students and other medico legal concerns need to be addressed before students are allowed to be volunteers. Student volunteers need to be trained before they can join a clinical team, screening team, laboratory team or a flu clinic. This training is largely being provided virtually by live video steaming, video webinars, and patient simulations including ventilator management training. As the students complete the training they can be matched to specific teams based on their assessment which is either done by an online quiz or by telephone/ video interviews.

\section{CONCLUSION}

COVID-19 pandemic has encouraged educators to improve the teaching learning strategies which will impact medical education in the years to come. The paradigm shift to e-learning during this outbreak may inspire medical schools to revisit and redesign their curriculum to more adaptable programs. The uniqueness of medical education makes innovation in its pedagogy a constant challenge. The reverberations of COVID -19 pandemic may forever leave an imprint on how medicine is taught. This pandemic also ushers the need to be future-ready with a contingency plan for continuing medical education in the event of any disaster which may require containment.

\section{REFERENCES}

1. Choules AP. The use of eLearning in medical education: a review of the current situation. Postgrad Med J. 2007; 83(978):212-216. https://doi.org/10.1136/pgmj.2006.054189
2. Vovides Y, Sanchez-Alonso S, Mitropoulou V and Nickmans G. The use of e-learning course management systems to support learning strategies and to improve self-regulated learning. Educational Research Review. 2007; 2(1), 64-74. https://doi.org/10.1016/j.edurev.2007.02.004

3. Dhir SK, Verma D, Batta M and Mishra D. E-Learning in Medical Education in India. Indian Pediatr. 2017 ;54(10):871-877. https://doi.org/10.1007/s13312-017-1152-9

4. O'Doherty D, Dromey M, Lougheed J, Hannigan A, Last J and McGrath D. Barriers and solutions to online learning in medical education - an integrative review. BMC Med Educ. 2018;18(1):130.

https://doi.org/10.1186/s12909-018-1240-0

5. Rose S. Medical Student Education in the Time of COVID-19. JAMA. 2020; 323(21):2131-2132. https://doi.org/10.1001/jama.2020.5227

6. Tabatabai S. COVID-19 impact and virtual medical education. J Adv Med Educ Prof. 2020; 8(3):140-143.

7. Alkhowailed MS, Rasheed Z, Shariq A, Elzainy A, El Sadik A, Alkhamiss $A$, et al. Digitalization plan in medical education during COVID-19 lockdown. Inform Med Unlocked. 2020;20:100432. https://doi.org/10.1016/j.imu.2020.100432

8. Sahi PK, Mishra D and Singh T. Medical Education Amid the COVID-19 Pandemic. Indian Pediatr. 2020;57(7):652-657. https://doi.org/10.1007/s13312-020-1894-7

9. Birch $\mathrm{E}$ and de Wolf M. A novel approach to medical school examinations during the COVID-19 pandemic. Med Educ Online. 2020; 25(1):1785680. https://doi.org/10.1080/10872981.2020.1785680

10. Sabzwari S. Rethinking Assessment in Medical Education in the time of COVID19. Med Ed Publish 2020; 9(1): 80. https://doi.org/10.15694/mep.2020.000080.1

11. Monaghan AM. Medical Teaching and Assessment in the Era of COVID-19. J Med Educ Curric Dev. 2020;7:2382120520965255 https://doi.org/10.1177/2382120520965255

12. Krieger $P$ and Goodnough $A$. Medical students, sidelined for now, find new ways to fight coronavirus. The New York Times. 23 March 2020. Accessed at www.nytimes.com/2020/03/23/health/ medical-students-coronavirus.html on 15 April 2020.

13. GMC UK. Information for medical students Available from: https:// www.gmc-uk.org/news/news-archive/coronavirus-informationand-advice/information-for-medical-students [Accessed 15 April 2020]

14. Miller DG, Pierson $L$ and Doernberg $S$. The Role of Medical Students During the COVID-19 Pandemic. Ann Intern Med. 2020; [Epub ahead of print 7 April 2020]. https://doi.org/10.7326/M20-1281

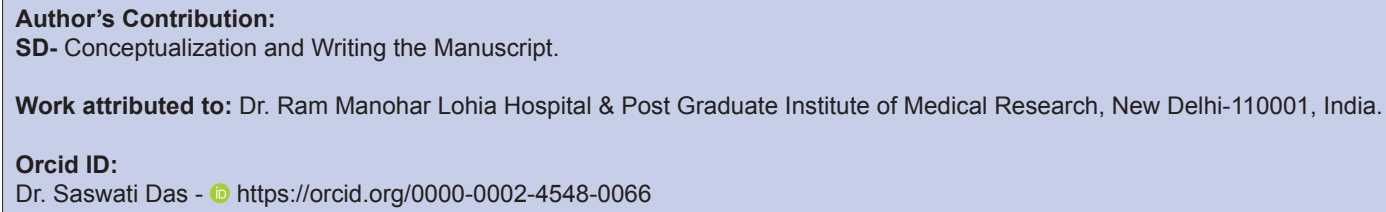

